\title{
Training youth caregivers to provide HIV education and support to orphans and vulnerable children in South Africa
}

Tobey C. Nelson

Eka Esu-Williams

Lungile Mchunu

Pinkie Nyamakazi

S'Fiso Mnguni

See next page for additional authors

Follow this and additional works at: https://knowledgecommons.popcouncil.org/departments_sbsr-hiv

Part of the Demography, Population, and Ecology Commons, Family, Life Course, and Society Commons, Gender and Sexuality Commons, International Public Health Commons, and the Medicine and Health Commons How does access to this work benefit you? Let us know!

\section{Recommended Citation}

Nelson, Tobey C., Eka Esu-Williams, Lungile Mchunu, Pinkie Nyamakazi, S'Fiso Mnguni, Katie D. Schenk, Catherine Searle, and Jennifer Redner. 2008. "Training youth caregivers to provide HIV education and support to orphans and vulnerable children in South Africa," Horizons Research Summary. Washington, DC: Population Council. 


\section{Authors}

Tobey C. Nelson, Eka Esu-Williams, Lungile Mchunu, Pinkie Nyamakazi, S'Fiso Mnguni, Katie D. Schenk, Catherine Searle, and Jennifer Redner 


\section{Training Youth Caregivers to Provide HIV EDUCATION AND SUPPORT TO ORPHANS AND Vulnerable Children in South Africa}

A study conducted in KwaZulu Natal suggests that utilizing trained youth caregivers is a feasible approach for reaching orphans and vulnerable children with HIV prevention education and support. Participants were enthusiastic about the program and demonstrated some improvements in HIV-related knowledge, attitudes, and communication. Lessons learned from the study have been used by The Valley Trust to strengthen the program and expand its scope.

he AIDS epidemic has led to a drastic increase in the number of children who have been orphaned following parental death. It has also resulted in large numbers of children considered vulnerable due to household circumstances that have affected their health and well-being, such as parental illness and poverty. Throughout sub-Saharan Africa, communities shouldering the heavy burden of AIDS face difficulties in meeting the diverse needs of these orphans and vulnerable children, including their need for education, psychosocial and nutritional support, livelihood opportunities, and help with caring for household

To read more about this study, go to

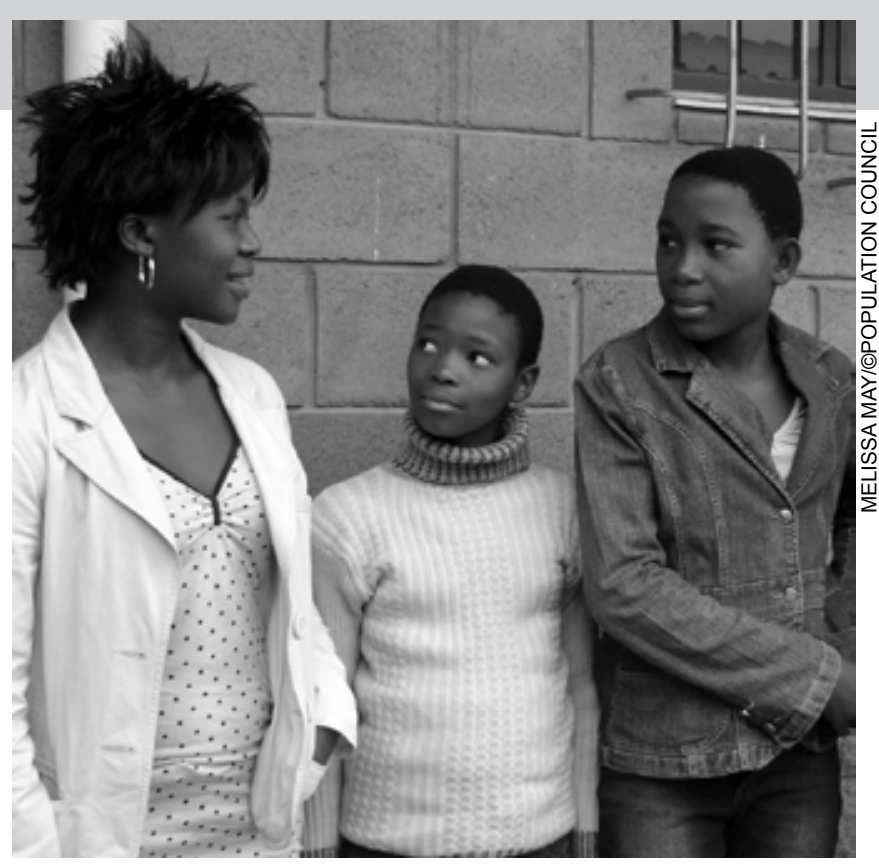

A volunteer youth caregiver discusses HIV prevention with learners attending The Valley Trust Youth Caregiver Program. members living with HIV. Innovative strategies are needed to increase the ability of communities to provide education, care, and support to children and families that have been affected by AIDS.

In South Africa's KwaZulu Natal province, adult HIV prevalence has been estimated to be 17 percent (Shisana et al. 2005). A study conducted in several communities in the province found that one out of five children aged 18 years or younger had lost one or both parents, while one out of four households was home to at least one orphan (Horizons 2004).

www.popcouncil.org/horizons/projects/SouthAfrica_YouthCaregivers.htm
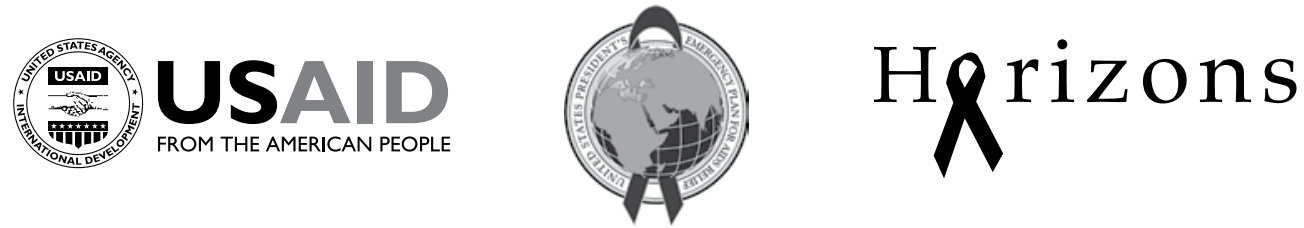
The peri-urban community of Valley of 1000 Hills, 20 miles northwest of Durban, has many low-income children living in single parent households. Here, Horizons partnered with The Valley Trust, a health service organization with more than 50 years of experience, to implement and evaluate a program for providing education and support to orphans and vulnerable children. This program was based on an intervention implemented by Horizons in Zambia, which showed that volunteer youth could be trained to provide care and support services to people living with HIV within their own communities. The Zambia study demonstrated the important role that young caregivers played in the lives of the children of people living with HIV (PLHIV). Building on these findings, the current study examined the role that young people can play in providing HIV education and support to orphans and vulnerable children in a school setting.

The school setting provides a platform to reach a large number of youth in developing countries with critical information about HIV. Research has shown that school-based sexuality and HIV education can contribute to risk reduction and behavior change (Haberland and Rogow 2007). In addition, schools, particularly those in KwaZulu Natal, offer an opportunity to reach youth who have been orphaned or rendered vulnerable due to HIV with support as well as HIV education.

\section{Methodology}

This intervention study utilized a pre-post test design to assess the feasibility and impact of building the capacity of older youth, aged 18-24 years, to provide HIV education and support to in-school orphans and vulnerable children within their communities.

At the start of the study, the research team conducted focus group discussions (FGDs) that involved 160 community members, including community health workers, primary school learners, school governing bodies, teachers, older youth, and parents. The FGDs explored community perceptions of orphans and vulnerable children, the feasibility of a school-based program targeting orphans and vulnerable children, and how best to structure such a program. Discussions were conducted in isiZulu, the local language, by a team of trained facilitators.

Survey data were collected from learners aged $11-15$ years at five primary schools in Valley of 1000 Hills. Researchers utilized an anonymous, pre-tested, interviewer-assisted, selfadministered questionnaire to measure learners' HIV knowledge, stigmatizing attitudes, and communication around HIV at baseline (October 2005) and at endline one year later (October 2006). After pre-tests revealed problems with a self-administered instrument, particularly around sexual behavior questions and skip patterns, the research team decided to use assistants who read each question and the possible responses aloud, and remained present to answer any queries from the learners as they completed the survey. This was done in order to minimize missing values while maintaining respondent confidentiality and anonymity. The endline survey also included questions to determine learners' acceptance of and satisfaction with the program. Both surveys were administered in isiZulu.

A total of 597 learners participated in the baseline survey and 524 completed the endline survey. Learners were eligible to participate in the study if they were between the ages of 11 and 15 years. The mean age for both the baseline and endline samples was 12 and the mean grade in school was sixth. The samples were evenly split between males and females.

A month before administering the surveys, The Valley Trust conducted informational meetings with parents/ guardians at each participating school. Parents/guardians were given consent forms at these meetings. One week before data collection The Valley Trust sent a reminder letter home with learners who had yet to return the form. Only those with written approval were eligible to participate in the research. The Valley Trust obtained verbal agreement (assent) from the participating learners as well. The percentage of learners who did not obtain guardian/parental consent at each survey round was negligible.

Halfway through the intervention period, a small nested qualitative study was conducted among learners to explore their understanding of the $\mathrm{ABC}$ (Abstinence, 
Be Faithful, and Condom Use) terms and behaviors. Six FGDs were conducted with program participants in three of the intervention schools. Groups were stratified by sex with each group consisting of eight males or eight females for a total of 48 participants. FGDs were conducted in isiZulu by a team of trained facilitators. Results of the nested study were used to inform the intervention message and content. Program participants who had completed the baseline survey and were attending the caregiver program were randomly selected from each of the three schools to participate.

Quantitative data were entered using EpiInfo and analyzed using SPSS software. Data from baseline and endline were analyzed as two cross-sectional rounds of data. Pearson's chi and t-tests were used to determine changes between baseline and endline and between intervention participants and non-participants at endline. Results are considered statistically significant at or below the 0.05 level. Qualitative data were translated into English when necessary and transcribed. A content analysis was conducted. Common themes emerging from the content analysis are reported in this summary.

The Ethical Review Board of the University of Witwatersrand and the Institutional Review Board of the Population Council provided ethical approval for the study. Permission was also sought and obtained from the principal at each participating school.

\section{Description of the Intervention}

\section{Intervention objectives}

The intervention, called The Valley Trust Youth Caregiver Program, focused on training older youth to provide HIV education, homework assistance, and psychosocial support to orphans and vulnerable children aged 11-15 years. The program aimed to increase HIVrelated knowledge, improve HIV communication skills, and decrease stigmatizing attitudes among participants.

The intervention was originally envisioned as a comprehensive HIV education and care and support intervention for orphans and vulnerable children. In addition to providing HIV education, homework support, and psychosocial support within the school setting, Horizons and The Valley Trust envisioned that the caregivers would be trained to identify and follow-up with the most vulnerable learners and provide them with further care and support in their homes. In addition, caregivers would be trained to advocate for vulnerable children in the community.

To inform the community and to gain support for the program, Horizons and The Valley Trust undertook a series of sensitization meetings with community members. These meetings revealed that principals, teachers, and parents, as well as the wider community, recognized the need for a program for orphans and vulnerable children in their schools. However, there was low receptivity to the home-based care and support and community advocacy components of the intervention. Moreover, the older youth who were recruited to become caregivers expressed concern about their safety and thought there would be community resistance to their involvement in home-based care and community advocacy. This was in contrast to the Horizons youth caregiver program in Zambia where the communities were more cohesive, individuals were more trusting of each other, and caregivers were less concerned about the potential risks involved with entering other people's homes. Because of community concerns, the homebased care and support and community advocacy components had to be dropped for the KwaZulu Natal study, therefore shifting the focus of the intervention to the provision of HIV education and psychosocial support in the school setting.

\section{Selection and training of caregivers}

The Valley Trust recruited volunteer caregivers from local youth groups and programs, and also solicited recommendations from local community health workers, school principals, and Valley Trust program staff. Box 1 lists the criteria used for selecting caregivers.

\section{Box 1 Criteria for selecting caregivers}

- Between the ages of 18-24.

- Completed grades 10-12.

- Closely connected to participating schools, either geographically or via community connections.

- Capacity to be trained in HIV education and support.

- Willingness to play sports and games.

- Commitment to working with children.

- Completed consent form and contact information sheet. 
A total of 98 youth (19 males and 79 females; mean age 23 years) were selected and participated in a comprehensive 5-day training that used a participantcentered approach to cover a wide variety of topics (see Box 2). A key component of the intervention was to provide HIV prevention education around the $A B C$ strategy. One day follow-up trainings were conducted periodically over the course of the intervention to address topics not covered during the initial training and discuss issues arising during the course of caregiving activities.

\section{Intervention activities}

Following the training, each youth caregiver was assigned to a local primary school. The number of caregivers assigned per school varied depending on school size and location. Caregivers visited their assigned school four times a week between Monday and Thursday for two hours per day over a six-month period to conduct a variety of activities (see Box 3 ).

Because Valley of 1000 Hills has a large number of orphans and children rendered vulnerable due to a range of issues, including poverty, HIV, and living in a single parent household, the project team decided to open up the program to all learners ages 11-15 years in each of the participating schools. This broad approach also

\section{Box 2 Youth Caregiver Training Curriculum}

Topic 1: Addressing the Needs of OVC

Topic 2: Identifying Community Resources

Topic 3: Personal Skills Development for Caregivers: Communication, facilitation, record keeping and monitoring, and time management

Topic 4: Facts about HIV and AIDS

Topic 5: HIV Prevention: ABC strategy

Topic 6: Stigma

Topic 7: Child Rights

Topic 8: Child Health and Nutrition

Topic 9: Gender

Topic 10: Child Abuse: Assertiveness and self esteem building

Topic 11: Counseling: Anger management, listening, and conflict resolution

Topic 12: Social Welfare: Child grants

\section{Box 3 Intervention activities}

- HIVIAIDS education.

- Child rights education.

- Homework assistance.

- Recreational activities.

- Theater and musical activities.

- Psychosocial support.

- Community outreach around HIV and the need for support programs for OVC.

had the added advantage of minimizing the potential effects of any stigma associated with participating in the intervention.

Caregivers were asked to complete daily monitoring forms with which The Valley Trust could track caregiver activities and attendance. The Valley Trust conducted routine process monitoring visits during which they reviewed monitoring forms and met with caregivers. Valley Trust researchers compiled monitoring findings into periodic reports which were submitted to Horizons. These forms and discussions provided The Valley Trust and Horizons with a clearer picture of what was happening on the ground.

\section{Key Findings}

\section{Participation by learners in the youth care- giver program was high.}

Over 70 percent of the 524 survey respondents at endline reported that they had participated in the program at least once. Females were significantly more likely to report participation in the program than males (60 percent vs. 40 percent: $\mathrm{p}<.01)$. Of the 397 learners who reported attending program activities, 80 percent reported that they had attended multiple times per week.

More than half ( 55 percent) of the program participants reported that they had been orphaned; 30 percent had experienced the death of a father only, 10 percent had experienced the death of a mother only, and 15 percent had experienced the death of both parents. Over 60 percent of program participants reported that they were living in a household headed by a single individual. 


\section{Participants responded positively to the youth caregiver program and reported benefits.}

Learners who participated in the youth caregiver program felt that they benefited from it, and reported positive changes as a result of their participation such as having greater knowledge about HIV transmission and prevention, being better able to protect themselves from HIV, feeling more accepted by their peers, having an easier time with schoolwork, and feeling more confident asking for help if their rights were violated (see Figure 1).

They have taught us how to prevent ourselves from getting AIDS and how we can care for those that are infected with HIV.

13-year-old female

They have taught us about the things that we need to know and do as children. They tell us things that will ensure that we are safe.

\section{2-year-old male}

The primary reason cited by participants for taking part in the program was to receive information about HIV, followed closely by the desire to participate in the recreational activities offered by the program and to obtain homework assistance.
Among the 127 respondents surveyed who did not attend The Valley Trust Youth Caregiver Program, the primary reasons given for non-participation were that their guardian(s)/parent(s) did not want them to return home from school late and that they had obligations after school that kept them from attending. These obligations included things such as tending to farm animals and completing household chores. Respondents also mentioned limited or no transportation after the program and the threat of robbery or violence when walking home late in the day as deterrents to participating in the program.

\section{Program participants demonstrated greater gains in HIV knowledge than non-partici- pants, but important gaps persisted among both groups.}

Survey respondents were asked to respond to a series of five statements to assess their HIV knowledge at baseline and endline. Between baseline and endline, program participants and non-participants both demonstrated increases in HIV knowledge. However these improvements were significantly greater among participants of the youth caregiver program (see Table 1 on the following page).

Figure 1 Self-reported improvements at endline as a result of participation in the program $(n=397)$

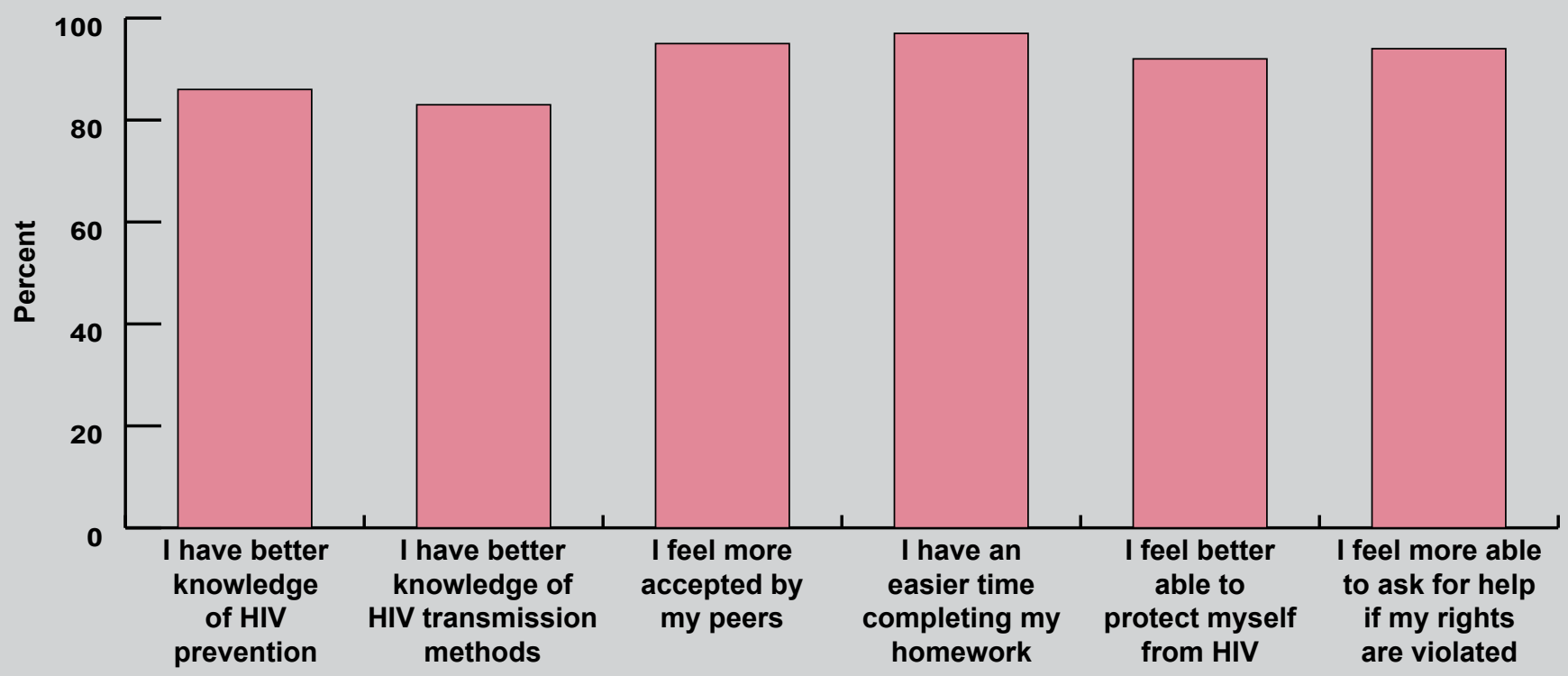


Table 1 Changes in HIV knowledge

\begin{tabular}{lc|cc}
\hline Statement (correct answer) & Baseline & \multicolumn{2}{|c}{ Endline } \\
& $\begin{array}{c}n=597 \\
\% \text { correct }\end{array}$ & $\begin{array}{c}\text { Non-participants } \\
\mathbf{n = 1 2 7} \\
\% \text { correct }\end{array}$ & $\begin{array}{c}\text { Participants } \\
\mathbf{n = 3 9 7} \\
\% \text { correct }\end{array}$ \\
\hline HIV and AIDS are the same thing (false) & 28 & $43^{*}$ & $49^{\star \wedge}$ \\
$\begin{array}{l}\text { You can get HIV from having unprotected sexual } \\
\text { intercourse (true) }\end{array}$ & 70 & $81^{*}$ & $93^{\star \wedge}$ \\
$\begin{array}{l}\text { A pregnant woman who is HIV positive can pass HIV to her } \\
\text { child during child birth (true) }\end{array}$ & 58 & 66 & $79^{\star \wedge}$ \\
$\begin{array}{l}\text { You can always tell if someone has HIV by the way they } \\
\text { look (false) }\end{array}$ & 51 & $63^{*}$ & $66^{*}$ \\
$\begin{array}{l}\text { You can get HIV from sharing utensils with someone who } \\
\text { has HIV or AIDS (false) }\end{array}$ & 29 & 32 & $46^{\star \wedge}$ \\
\hline
\end{tabular}

${ }^{*} p \leq .01$ between baseline and endline

${ }^{\wedge} p \leq .01$ between participants and non-participants at endline

Male and female intervention participants had comparable knowledge across all but two of the variables at endline, "You can always tell if someone has HIV by the way they look" (59 percent of males vs. 70 percent of females answered correctly) and "You can get HIV from sharing utensils with someone who has HIV or AIDS" (37 percent of males vs. 53 percent of females answered correctly). For these two variables females were significantly $(\mathrm{p}<.01)$ more likely to answer correctly.

While the proportion of respondents who answered correctly increased from baseline to endline for every statement assessing HIV knowledge, a high percentage of program participants still had misconceptions about HIV transmission after participating in the program. For example, over 50 percent of program participants incorrectly believed that HIV is spread by sharing utensils and 44 percent incorrectly believed that you can tell if someone has HIV by the way they look.

At endline program participants were significantly more likely to be able to name three or more methods of HIV prevention than non-participants (23 percent vs. 13 percent; $\mathrm{p}<.05)$. The top three methods of prevention listed by survey respondents were condom use, abstinence, and avoiding sharing razors with infected persons. Program participants were significantly more likely $(\mathrm{p}<.05)$ to list one of these top three prevention methods that non-participants. However, although program participants were more likely to name three methods of HIV prevention, over three-fourths were still unable to do so.

More than half of the program participants identified condom use and abstinence as methods of HIV prevention at endline, but only 2 percent identified being faithful as a method of preventing HIV (see Figure 2). When asked about methods to prevent HIV at endline, non-participants were significantly less likely $(\mathrm{p}<.01)$ to report any of the three $\mathrm{ABC}$ prevention behaviors than program participants. Female participants were significantly more likely to report abstinence as a method of prevention than males (58 percent vs. 42 percent; $\mathrm{p}<.05)$.

Qualitative data from program participants support these findings. Focus group participants were able to engage in discussions about condoms, implying a general understanding of condom use as a method of HIV prevention. Program participants also had a good understanding of the meaning of abstinence. However, being faithful was the least recognized of the three terms and behaviors in the context of HIV prevention. 


\section{Participants perceived barriers to the practice of the ABC behaviors.}

Almost all male and female learners who participated in the nested study's focus group discussions agreed that abstinence, being faithful, and condom use were not common behaviors in their community and indicated that practicing these behaviors was difficult or even impossible.

Respondents generally agreed that being abstinent and faithful to one partner were only possible among the very young (under age 14) and the very old, and not among adolescents over age 14 and the general adult population. During these discussions participants did not make a distinction between the ages at which abstinence is more appropriate as opposed to being faithful.

Female and male respondents reported that the need for financial security and the desire for material goods often drive males and females to engage in sexual behavior. Social pressure to have children and peer pressure were also mentioned as barriers to practicing abstinence, particularly for females.

[When a girl] abstains her friends call her stupid and she feels left out so she starts to have sex.

14 -year-old female
Peer pressure and peer norms were also cited as barriers to faithfulness for males.

[Peers] ask you about your relationships and the number of girlfriends you have. When you tell them that you don't have a girlfriend or you have only one girlfriend they laugh at you and say that you are stupid.

15-year-old male

The nested study data also revealed that respondents felt that condom use was generally reserved for married people who used condoms primarily for contraceptive purposes. Respondents routinely singled out adolescents (youth over age 14) and unmarried young adults as the group for whom condom use was the least possible for a variety of reasons.

The majority of respondents described the desire for children and a distrust of the efficacy of condoms as some of the barriers to condom use in their community, particularly among adolescents.

\section{[Adolescents] don't use condoms because they} want babies.

13-year-old female

A condom is of no use because it bursts when one is busy using it.

14-year-old male

\section{Figure 2 Knowledge of $A B C$ prevention methods at endline}

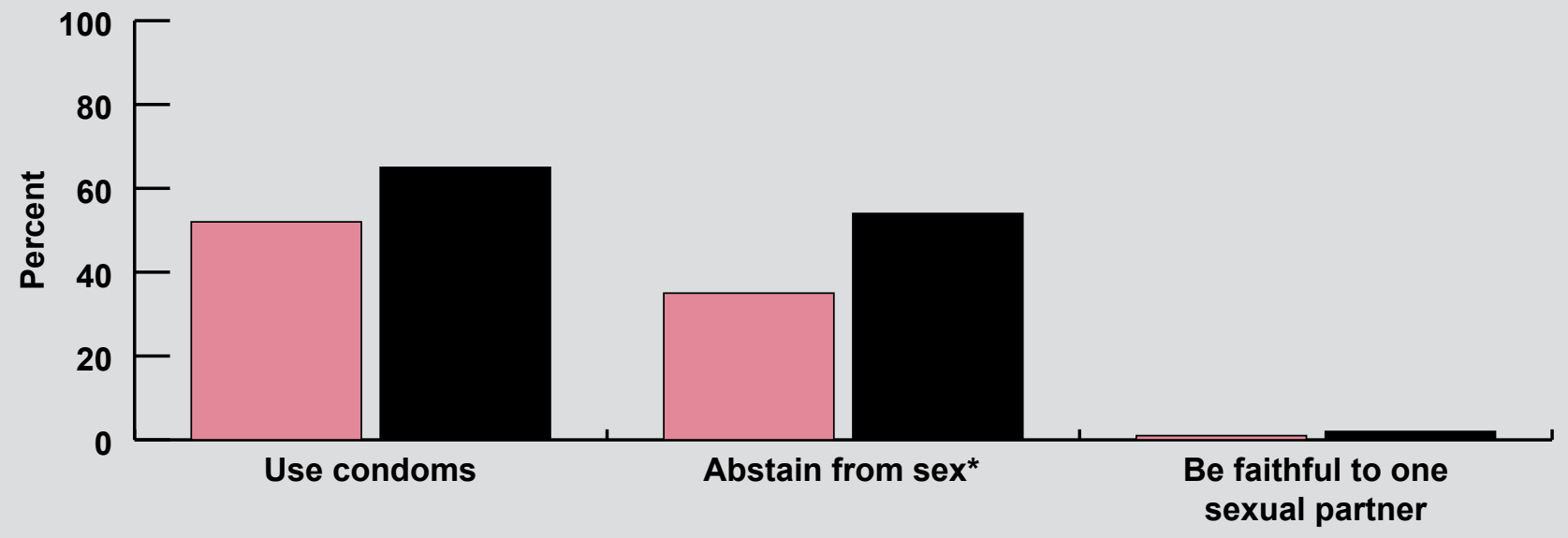

Non-participants $(n=127)$

Participants $(n=397)$

${ }^{*} p<.01$ 
When answering questions in the nested study, several respondents suggested that for adults to ask a partner to use a condom would imply a lack of trust and that they could be risking physical violence if their partner suspected infidelity. Few respondents mentioned that condom use was immoral or considered to be a "bad" behavior.

\section{Program participants demonstrated positive attitudinal changes toward people living with HIV, however stigma remained a problem.}

Between baseline and endline, survey respondents demonstrated significant improvements in their attitudes toward people living with HIV. For example, while both groups showed improvement, more participants reported at endline that they would be willing to buy food from a person living with HIV than non-participants. By endline, program participants demonstrated significantly greater reductions in their stigmatizing attitudes than non-participants (see Table 2).

Caregivers have taught us to treat people that are HIV positive like other people; we shouldn't treat them different.

\section{2-year-old male}

At endline, survey respondents were asked several additional questions about value-driven stigma. Ap- proximately half of respondents believed that AIDS is a punishment for bad behavior and that people living with HIV should be ashamed of themselves. Over 60 percent of respondents reported that they would feel ashamed if they were infected with HIV, and over 40 percent would be afraid to tell anyone if they were infected with HIV. There were no significant differences between program participants and non-participants on these items.

\section{Participants reported an increase in HIV- related communication.}

One of the main objectives of the program was to increase communication about HIV. At baseline and endline, survey respondents were asked how often during the preceding six months they had communicated about HIV within different contexts. At endline, program participants were significantly more likely than non-participants to report having discussed HIV at school (83 percent vs. 52 percent: $\mathrm{p}<.01$ ) and at home (39 percent vs. 27 percent: $\mathrm{p}<.05$ ) (see Figure 3).

The communication that we have initiated is important. Because [participants] are so happy to see me when I come to see them, they seem to hear and see the importance of what I want to tell them. What is also encouraging is that they are asking questions as well... This means that

\section{Table 2 Changes in attitudes toward people living with HIV}

\begin{tabular}{lc|cc}
\hline & $\begin{array}{c}\text { Baseline } \\
\text { \% }=597 \\
\text { answering yes }\end{array}$ & $\begin{array}{c}\text { Endline } \\
\text { Non-participants } \\
\mathbf{n = 1 2 7} \text { answering yes }\end{array}$ & $\begin{array}{c}\text { Participants } \\
\mathbf{n}=397 \\
\text { answering yes }\end{array}$ \\
\hline $\begin{array}{l}\text { Would you be willing to buy food from a } \\
\text { person who had HIV? }\end{array}$ & 21 & $31^{*}$ & $41^{* \wedge}$ \\
$\begin{array}{l}\text { Would you be willing to play with a child } \\
\text { whose parent has died of AIDS? }\end{array}$ & 39 & $61^{*}$ & $73^{* \wedge}$ \\
$\begin{array}{l}\text { Would you be willing to care for a family } \\
\text { member who was suffering from AIDS? }\end{array}$ & 42 & $74^{*}$ & $86^{* \wedge}$ \\
\hline
\end{tabular}

${ }^{*} p \leq .01$ between participants and non-participants at endline

$\wedge p \leq .05$ between participants and non-participants at endline 
Figure 3 Changes in communication about HIV (\%)

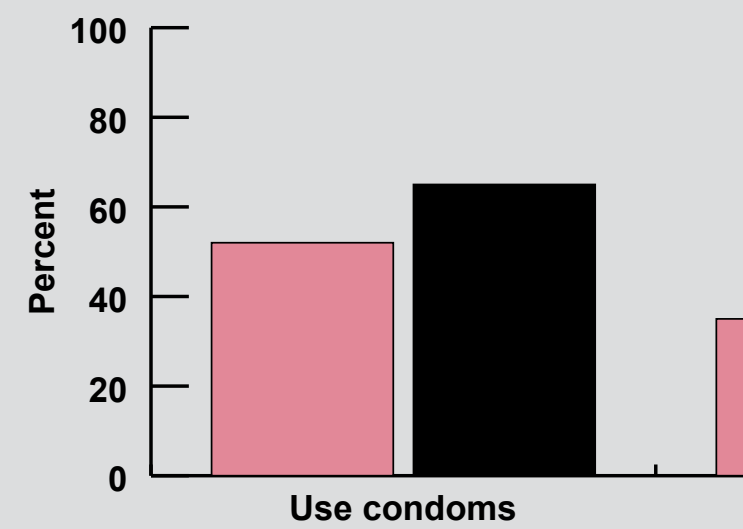

$$
\text { Non-participants }(n=127) \quad \square \text { Participants }(n=397)
$$

${ }^{*} p \leq .01$ between baseline and endline

${ }^{\wedge} p \leq .05$ at endline between participants and non-participants

can think for themselves and they understand the dangers that are out there.

Female caregiver

There are a lot of questions that these children ask from us and I just wonder to myself if I wasn't there, where or to whom will these children ask these questions.

Female caregiver

Almost one out of five (17 percent) program participants reported that they did not discuss HIV at school over the intervention period. One explanation for this is that the program was operated as a drop-in program and participation was voluntary. While one of the core activities of the program was to discuss HIV, the youth caregivers conducted numerous activities and engaged in group and individual discussions around a wide range of health topics. Program participants may have chosen to attend the program on days when HIV was not the main topic.

\section{Volunteer youth caregivers reported satisfac- tion with the program.}

The trained youth caregivers indicated that they had found their own participation in the program to be worthwhile, citing an increase in their knowledge and skills. They also felt that they had gained valuable work/volunteer experience through the program and were proud to have served their community.

I learned a lot in the trainings that I received. It made my work a bit easier. I used the information not only with the children that I worked with but I also shared it with my friends and peers, some people that are not even part of the program.

\section{Female caregiver}

I think what we did was really important, visiting [orphans and vulnerable children] at school. The truth is, most children are not as happy as we think when they are at home. The few minutes that they spent [with us] at school were quite special to them. We could see that some of them didn't even want to leave in the afternoon, they were so excited.

Female caregiver

I experienced bad things as a child so I just thought maybe I could prevent a child from going through the same things that I went through. Maybe the life experience that I have could help other children.

Female caregiver 


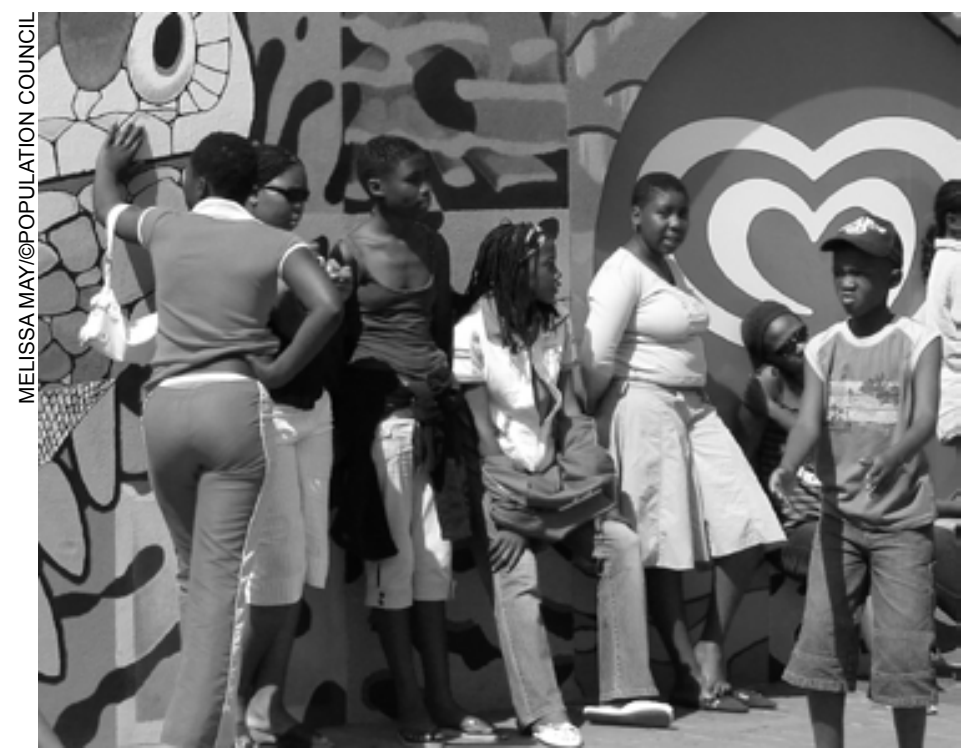

Learners attending the Valley Trust Youth Caregiver Program at a KwaZulu-Natal primary school.

\section{Volunteer youth caregivers felt limited in meet- ing the needs of program participants.}

At endline, the trained youth caregivers reported that they felt limited in their abilities to meet all the needs of program participants. For example, caregivers reported that many program participants were living with or caring for someone living with tuberculosis (TB), and that they could have benefited from information on TB that they did not have.

As youth caregivers worked to establish relationships with program participants and encouraged open communication, it became evident that many of them demonstrated a need for grief and/or bereavement counseling. Caregivers reported feeling unable to help them with issues related to grief or to answer questions about death.

Caregivers also reported that they felt limited in offering practical assistance in accessing social grants and in their ability to address children's subsistence and material needs.

\section{The attrition rate among volunteer youth caregivers was high.}

Although 98 youth were recruited and trained to serve as volunteer caregivers, almost half dropped out of the program between the baseline and endline surveys. Caregivers who left the program, as well as those caregivers who remained with the program, cited lack of financial compensation and limited or no transportation as the two primary reasons for caregiver drop out. Additional reasons cited by caregivers for turnover were negative community perceptions of volunteerism, local political divisions, and poaching by competing NGO programs.

I would like to continue with the program but there isn't anything that we are getting from the project. If you could even give us something like [sandals] because we are wearing out our own shoes that we bought with our money for a program that we love but it is not giving us anything back.

Female caregiver

People will ask me "where are you going so late" and I will [tell them] and they would ask if I am getting [paid] anything and I would say no they will look at me like I'm crazy or something.

Female caregiver

Youth caregivers also reported that they received limited support from friends and family. Some even experienced discouragement.

Friends are not encouraging, they say we are wasting our time although they themselves are not employed and staying at home.

Female caregiver

\section{Principals, teachers, and parents/guardians were supportive of the program.}

The trained youth caregivers reported that they experienced some initial resistance from school principals, teachers, and parents. However, over time, a number of encouraging changes were noted: school principals began to eagerly offer school space for the program, and teachers requested program materials for use in their classrooms and indicated that they were grateful to the youth caregivers for teaching their students about HIV and providing them with psychosocial support.

There are children that are orphaned but there isn't anything that [teachers] can do for them. 
That is the honest truth. We know about them

but what can we do? We rely on people like you [Valley Trust Caregivers] to help us.

Female teacher

Focus group data collected at endline revealed that the trained youth caregivers were receiving support and positive feedback from parents.

We have been praised by some mothers for the work that we do, especially with the abstinence work that we have been doing. Some of the parents cannot talk to their children about things that relate to sex and sexuality. They were grateful that we have done that for them. The children talk with the parents about the things that we teach them in school.

Female caregiver

I see that the children are enthusiastic about school now, even the teachers are testifying to that. When the last bell of school rings, they no longer rush home, they wait for us to come and start work with them. The parents know that if they are not at home at a particular time, they are with us and learning more with us.

Female caregiver

\section{Conclusions and Lessons Learned for Replication and Scale-up}

This study demonstrated that trained volunteer youth caregivers operating in a school-based setting can reach children who are orphaned and rendered vulnerable by their household and community circumstances. The education and support that they provided likely contributed to improvements in HIV-related knowledge, attitudes, and communication among program participants, given that the gains they made were often greater than those of non-participants. Improvements in knowledge, attitudes, and communication among all survey respondents over the course of 12 months, whether or not they participated in the program, is also an encouraging finding indicating that in-school youth in this community are getting HIV education from multiple sources.

Lessons learned from the study include the following:

- School-based HIV education and support programs are a good way to reach orphans and vulnerable children in communities where there are barriers to home and community-based efforts. In addition, programs working in the school setting supplement and enhance the work being done by the Department of Education.

- Although some positive knowledge and attitudinal changes were associated with program participation, a more intense training for youth caregivers, better retention of caregivers, and a longer intervention period may be needed to see greater improvements across all knowledge and attitudinal variables.

- HIV prevention messages must be consistent, clear, and age appropriate. Programs that utilize the ABC HIV prevention strategy should go beyond the provision of $\mathrm{ABC}$ messages and include contextually specific skills-building activities to address the barriers to the $\mathrm{ABC}$ behaviors.

- Ongoing monitoring of and follow-up trainings for youth caregivers is necessary to equip them with the information and skills that they need to address the specific and diverse needs of the children in their communities. At the same time, the range of care and support needs that can be met by trained youth volunteer caregivers in a school-based setting are limited. Caregivers must be trained to clearly communicate to children, parents/guardians, and stakeholders about the range of services they are able and unable to provide.

- Developing partnerships and linkages with other programs and services in the community is essential in order to address the children's more acute needs that youth caregivers cannot manage.

- Obtaining and maintaining community and stakeholder acceptance and involvement is essential.

- An intense sensitization process at the initial stage of the program and the continued involvement of the community and stakeholders throughout the implementation may promote greater support of youth caregivers, generate more community and parental/ guardian support, and enhance the program's access to community members and schools.

- Programs must identify ways to retain and motivate youth caregivers. Lack of compensation was identified as a barrier for volunteer caregivers. Providing caregivers with financial remuneration may encourage caregivers to maintain pride and respect in their work and reduce attrition rates. In the absence of financial incentives, providing caregivers with food parcels or goods such as shoes or t-shirts/uniforms could be a way to incentivize volunteer caregiver participation. 


\section{Next Steps}

Following this study, The Valley Trust received funding to expand the program to five new geographic areas and to broaden its mandate to include vocational training and nutritional support, as well as shelter, care, and child protection interventions. The program has developed linkages with other Valley Trust programs and community organizations to provide direct health and legal services to orphans and vulnerable children in the program. The Valley Trust has recruited new youth caregivers and now provides them a monthly stipend. The program has also expanded to include home visits/ follow-up when necessary. $\mathbb{R}$

January 2008

\section{References}

Shisana, O. et al. 2005. South African National HIV Prevalence, HIV Incidence, Behavior and Communication Survey, 2005. Cape Town: HSRC Press.

Horizons Program. 2004. "Challenges faced by households in caring for orphans and vulnerable children," Horizons Research Update. Washington, DC: Population Council.

Haberland, N. and D. Rogow. 2007. "Sexuality and HIV education: Time for a paradigm shift," Transitions to Adulthood, Brief 22. New York: Population Council.
The research team wishes to thank the volunteer youth caregivers and learners who participated in The Valley Trust Youth Caregiver Program. In addition we would like to thank the participating communities and schools in the Valley of 1000 Hills.

Study investigators include: Tobey C. Nelson, Horizons/International Center for Research on Women; Eka Esu-Williams and Catherine Searle, formerly of Horizons/Population Council; Katie Schenk, Horizons/Population Council; Lungile Mchunu, Pinkie Nyamakazi, S'Fiso Mnguni, The Valley Trust. Jennifer Redner, formerly of Horizons/ Population Council provided data analysis support.

Suggested citation: Nelson, Tobey C., Eka Esu-Williams, Lungile Mchunu, Pinkie Nyamakazi, S’Fiso Mnguni, Katie Schenk, Catherine Searle, and Jennifer Redner. 2008. "Training youth caregivers to provide HIV education and support to orphans and vulnerable children in South Africa," Horizons Research Summary. Washington, DC: Population Council.

\section{Hqrizons 4}

Population Council/Horizons

Communications Unit

4301 Connecticut Avenue, NW

Suite 280

Washington, DC 20008

\section{(P Population Council}

Tel: 202-237-9400

Fax: 202-237-8410

horizons@popcouncil.org

www.popcouncil.org/horizons
This research summary is made possible by the generous support of the American people through the United States Agency for International Development (USAID) and the President's Emergency Plan for AIDS Relief under the terms of HRN-A-00-97-00012-00. The contents are the responsibility of the Horizons Program and do not necessarily reflect the views of USAID or the United States Government. 